\title{
A database of paleoceanographic sediment cores from the North Pacific, 1951-2016
}

\author{
Marisa Borreggine $^{1}$, Sarah E. Myhre ${ }^{1,2}$, K. Allison S. Mislan ${ }^{1,3}$, Curtis Deutsch ${ }^{1}$, and \\ Catherine V. Davis ${ }^{4}$ \\ ${ }^{1}$ School of Oceanography, University of Washington, 1503 NE Boat Street, Box 357940, \\ Seattle, WA 98195-7940, USA \\ ${ }^{2}$ Future of Ice Initiative, University of Washington, Johnson Hall, Room 377A, Box 351360, \\ Seattle, WA 98195-1360, USA \\ ${ }^{3}$ eScience Institute, University of Washington, 3910 15th Ave NE, Box 351570, Seattle, WA 98195, USA \\ ${ }^{4}$ School of Earth, Oceans, and the Environment, University of South Carolina, 701 Sumter Street, \\ Earth and Water Science Building, Room 617, Columbia, SC 29208, USA
}

Correspondence to: Sarah E. Myhre (semyhre@uw.edu)

\author{
Received: 6 June 2017 - Discussion started: 22 June 2017 \\ Revised: 25 August 2017 - Accepted: 2 September 2017 - Published: 28 September 2017
}

\begin{abstract}
We assessed sediment coring, data acquisition, and publications from the North Pacific (north of $30^{\circ} \mathrm{N}$ ) from 1951 to 2016. There are 2134 sediment cores collected by American, French, Japanese, Russian, and international research vessels across the North Pacific (including the Pacific subarctic gyre, Alaskan gyre, Japan margin, and California margin; 1391 cores), the Sea of Okhotsk (271 cores), the Bering Sea (123 cores), and the Sea of Japan (349 cores) reported here. All existing metadata associated with these sediment cores are documented here, including coring date, location, core number, cruise number, water depth, vessel metadata, and coring technology. North Pacific sediment core age models are built with isotope stratigraphy, radiocarbon dating, magnetostratigraphy, biostratigraphy, tephrochronology, \% opal, color, and lithological proxies. Here, we evaluate the iterative generation of each published age model and provide comprehensive documentation of the dating techniques used, along with sedimentation rates and age ranges. We categorized cores according to the availability of a variety of proxy evidence, including biological (e.g., benthic and planktonic foraminifera assemblages), geochemical (e.g., major trace element concentrations), isotopic (e.g., bulk sediment nitrogen, oxygen, and carbon isotopes), and stratigraphic (e.g., preserved laminations) proxies. This database is a unique resource to the paleoceanographic and paleoclimate communities and provides cohesive accessibility to sedimentary sequences, age model development, and proxies. The data set is publicly available through PANGAEA at https://doi.org/10.1594/PANGAEA.875998.
\end{abstract}

\section{Introduction}

Paleoceanographic sediments provide the sedimentary, geochemical, and biological evidence of past Earth system changes. Sediment cores produce robust reconstructions of large oceanographic provinces and provide insight into earth system mechanistic hypotheses. However, there is not a common repository for paleoceanographic data and publications, and this lack of centralization limits the efficacy of the earth science community in directing research efforts. For the
North Pacific, such ongoing mechanistic hypotheses include deep ocean circulation (e.g., Rae et al., 2014; De Pol-Holz et al., 2006), deep water and intermediate water formation and ventilation (e.g., Knudson and Ravelo, 2015a; Zheng et al., 2000; Cook et al., 2016), and changes in the oceanicpreformed nutrient inventories (e.g., Jaccard and Galbraith, 2013; Knudson and Ravelo, 2015b), as well as more regional mechanisms such as sea ice extent (e.g., Max et al., 2012), upwelling intensity (e.g., Di Lorenzo et al., 2008; Hendy 
et al., 2004), local surface ocean productivity (e.g., Serno et al., 2014; Venti et al., 2017), and terrigenous and marine fluxes of iron (e.g., Davies et al., 2011; Praetorius et al., 2015).

Paleoceanographers have benefited from the use of large databases of climate data in the past, such as CLIMAP Project Members (1981) (Climate: Long-Range Investigation, Mapping, Prediction), which produced globally resolved temperature records for the Last Glacial Maximum (LGM) and aimed to determine climate system sensitivity from paleoclimate reconstructions (Hoffert and Covey, 1992). The PaleoDeepDive project employed a similar approach to the systematic extraction of archival data and constructed a new way to assess and engage with paleobiological data (Zhang, 2015). These projects are examples of international research teams approaching the same limit - extraction and organization of dark data - that arises when creating comprehensive paleoreconstructions.

\subsection{Assembling a paleoceanographic database}

A clear need exists for high quality paleoenvironmental reconstructions to fit the North Pacific into a climate global framework because the role this enormous ocean basin plays in earth system changes remains relatively unclear in comparison to the Southern and Atlantic oceans. To address the collective need, we present here a new database of North Pacific paleoceanographic research efforts along with the broad findings of our census of coring metadata, age model development, and proxy publications. We address the following questions in this paper to supplement and provide context for our database:

1. Where have sediment cores been extracted from the North Pacific seafloor (north of $30^{\circ} \mathrm{N}$, including the Pacific subarctic gyre, Alaskan gyre, Japan margin, and California margin), the Bering Sea, the Sea of Okhotsk, and the Sea of Japan? What metadata are available in published cruise reports or peer-reviewed investigations, including core name, recovery date, recovery vessel and scientific agency, latitude and longitude, water depth, core length, and coring technology?

2. For sediment cores with published age models, what lines of evidence were used to develop the chronological age of the sediment, what is the age range from core top to core bottom, and what are the sedimentation rates?

3. What lines of sedimentary, geochemical, isotopic, and biological proxy evidence are available for each sediment core?

4. How has the state of North Pacific research efforts and reporting changed since the beginning of paleoceanographic expeditions?

\subsection{Paleoceanographic age models, proxies, and nomenclature}

Marine sedimentary age models tie the sedimentary depth (in meters below sediment surface) to calendar age (ka, thousands of years and/or Ma, millions of years). Not all sedimentary chronologies are of the same quality, and often age models are iteratively refined. Age models are developed with many different dating techniques, which are dependent upon the quality, preservation, and age of the sediments, as well as the investigative priorities of research teams and the proximity of other well-developed sedimentary chronologies. Paleoceanographic proxies, including biological, isotopic, geochemical, and sedimentary observations and measurements, address large thematic questions in the reconstruction of ocean environments, including ocean temperature, paleobiology, seafloor geochemistry, sea ice distribution, and additional sedimentary analyses.

Sediment cores are often represented by their cruise-core unique identifier, which has the general format "cruise namecore number". The cruise number is generally indicative of the research vessel employed and the year of the expedition. For example, L13-81 is the 13th cruise of S. P. Lee in 1981, MR06-04 is the 4th cruise of R/V Mirai in 2006, and YK0712 is the 12th cruise of R/V Yokosuka in 2007. Often the core number will be preceded or followed by a PC (piston core), MC (multicore), TC (trigger core), or GC (gravity core) to signify the coring technology. The sediment core B37-04G is the fourth gravity core from the 37th cruise of R/V Professor Bogorov, and EW9504-11PC is the 11th piston core from the fourth cruise of R/V Maurice Ewing in 1995. However, this nomenclature is not comprehensive. For example, cores affiliated with iterations of the International Ocean Discovery Program are represented by the program abbreviation and their hole number (i.e., ODP Hole 1209A). Cruise name or number is unknown for many cores, and in these cases the core is referred to by number.

\section{Methods}

Here we assembled a database from peer-reviewed publications, publicly available online cruise reports, and print-only cruise reports available through the University of Washington library network. Detailed metadata were reported for cores where it is available, commonly from cruise reports, including water depth (in meters), recovery year, latitude and longitude, coring technology, and core length (in meters). Summary details regarding affiliated research vessels and institutions were gathered from publications or cruise reports. Cruise reports were commonly available for research expeditions affiliated with JAMSTEC, GEOMAR, and the Scripps Institution of Oceanography and were less commonly available for older cores. All evidence used in age model development was reported along with sedimentation rates and the sedimentary age ranges to provide investigators with the ca- 

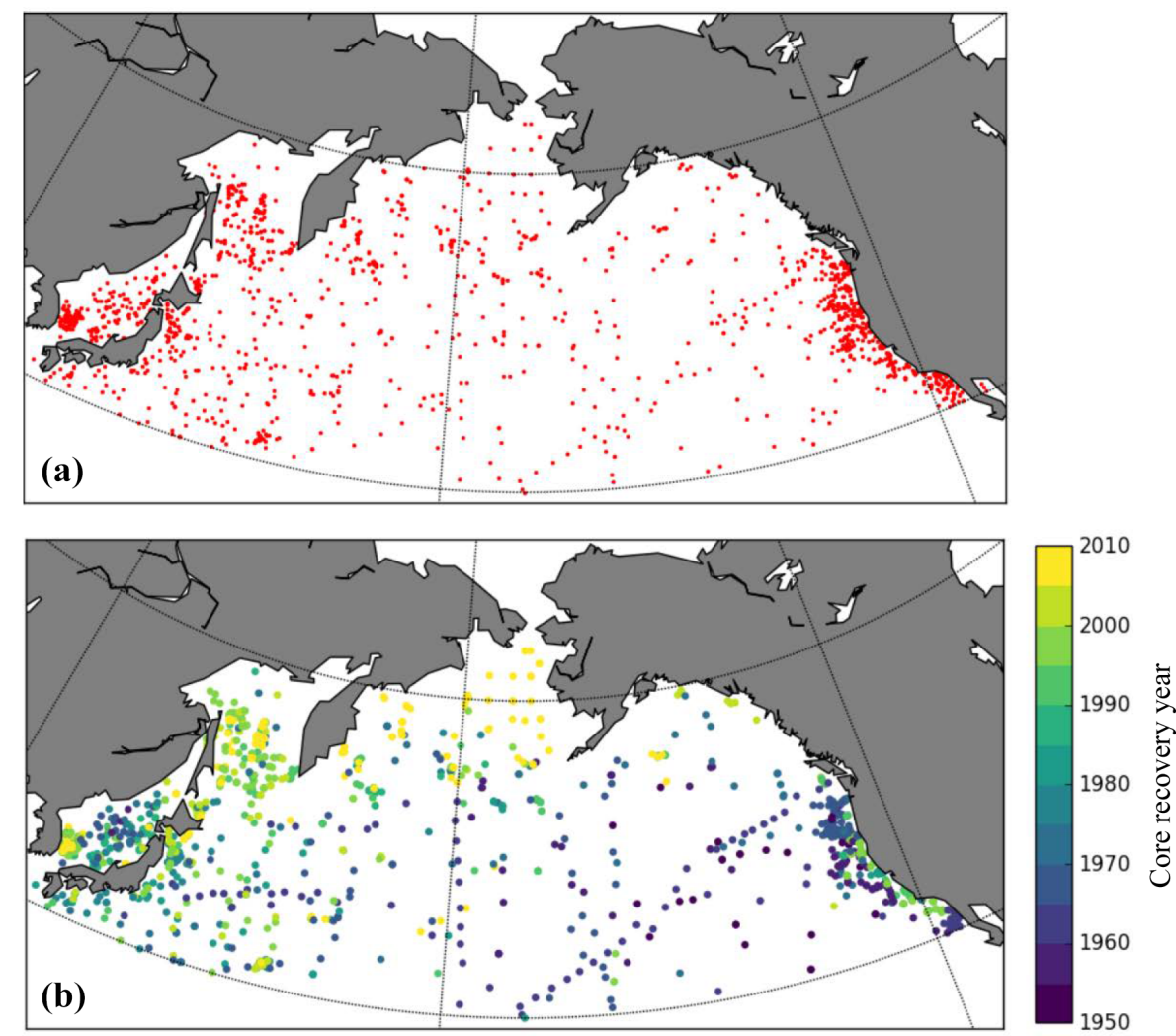

Figure 1. Location and recovery year of marine sediment cores from the North Pacific and marginal seas. (a) Sediment cores in the North Pacific (above $30^{\circ} \mathrm{N}$ ) published with latitudes and longitudes ( 354 additional cores were documented in either cruise reports or peer-reviewed publications without latitude and longitude). (b) Sediment cores published with an associated core recovery year ranging from 1951 to 2010. This age range corresponds with the color bar (495 cores have been published in either cruise reports or peer-reviewed publications without a recovery year).

pacity to quickly evaluate specific cores that meet the investigative priorities. For each core, paleoceanographic proxies and associated publications are documented to provide an efficient resource for assessing the availability and quality of different lines of paleoenvironmental information. In addition, we evaluated the annual number of age models published (using any dating technique), age models published specifically with radiocarbon dating, publications generated, sediment cores collected, research cruises completed, and the mean number of proxies generated per core.

\section{Results}

\subsection{Sediment coring and metadata}

We documented 2134 sediment cores and 283 marine geology research cruises above $30^{\circ} \mathrm{N}$ from 1951 to 2016 in the North Pacific, the Bering Sea, the Sea of Japan, and the Sea of Okhotsk (Fig. 1, Table 1). The majority of sediment cores were extracted from the northern subarctic Pacific (1391 cores) followed by the Sea of Japan (349 cores), the Sea of Okhotsk (271 cores), and the Bering Sea (123 cores).
Many of the oldest cores in this oceanographic province came from the central abyssal Pacific and were associated with the Deep Sea Drilling Project. Cores were extracted from the North Pacific from 1951 to 2010, and the oldest age models extend to $120000 \mathrm{ka}$ (Fig. 1, Table 1). Metadata associated with sediment cores or marine research cruises are frequently unavailable or omitted from publications affiliated with sediment cores. For example, 495 cores are in the literature without a recovery year, 354 sediment cores were published without latitude and longitude, and 642 cores were reported without specifying the coring technology used (Tables 1 and 2). Moreover, 1210 sediment cores reported in our database were identified in supplemental tables within publications, but no original cruise reports or peer-reviewed publications otherwise report on these cores.

\subsection{Sediment chronologies}

In the North Pacific, 519 marine sediment cores have published age models, and 266 of these chronologies are generated with the radiocarbon dating $\left({ }^{14} \mathrm{C}\right)$ of planktonic foraminifera, molluscs, or terrigenous material like bark or 
Table 1. Regional summary of sediment core database for the Bering Sea, North Pacific, Sea of Japan, and Sea of Okhotsk, including number of cores recovered, the regional percent $(\%)$ of cores reported with latitude and longitude, number of research cruises, total regional publication count, count of cores with no peer-reviewed publications or cruise report, the range of core recovery years, the regional percent (\%) of cores reported with recovery years, and the range of recovered core water depths (m b.s.l.).

\begin{tabular}{|c|c|c|c|c|c|}
\hline Region & Bering Sea & North Pacific & Sea of Japan & Sea of Okhotsk & Total \\
\hline Count of cruises & 24 & 179 & 78 & 31 & 283 \\
\hline Count of publications & 70 & 306 & 114 & 90 & 565 \\
\hline Count of cores with no publications* or cruise report & 61 & 849 & 172 & 128 & 1210 \\
\hline Number of cores recovered & 123 & 1391 & 349 & 271 & 2134 \\
\hline Percent of regional cores $(\%)$ reported with latitude and longitude & 91.9 & 81.9 & 77.7 & 91.9 & 83.4 \\
\hline Range of core recovery years & $1957-2009$ & $1951-2009$ & $1957-2010$ & 1972-2009 & $1951-2010$ \\
\hline Percent of regional cores (\%) reported with recovery year & 87 & 68.9 & 96.9 & 98.5 & 76.8 \\
\hline Range of recovered core water depths (m b.s.l.) & $33-3930$ & $21-9585$ & $129-5986$ & $105-8180$ & 21-9585 \\
\hline
\end{tabular}

* These cores are listed in large data tables in auxiliary publications, but the original reporting is not publicly available.

Table 2. Percent of regional cores reported with coring technology and the number of cores recovered in the North Pacific and marginal seas by coring technology. Additional reported coring technologies include the less often utilized hydrostatic cores, kasten cores, Asura cores, pressure cores, and trigger cores.

\begin{tabular}{lrrrr}
\hline Region & Bering Sea & North Pacific & Sea of Japan & Sea of Okhotsk \\
\hline \% of regional cores reported with drilling technology & 75.6 & 72.1 & 60.2 & 68.6 \\
No. of piston cores & 33 & 476 & 177 & 67 \\
No. of gravity cores & 11 & 250 & 15 & 73 \\
No. of box cores & 2 & 78 & 1 & 1 \\
No. of riserless drilling cores & 7 & 52 & 0 & 0 \\
No. of multicores & 33 & 39 & 1 & 39 \\
No. of Phleger cores & 0 & 15 & 0 & 0 \\
No. of jumbo piston cores & 4 & 10 & 0 & 0 \\
\hline
\end{tabular}

wood fragments (Fig. 2). Radiocarbon dating is the most common region-wide chronological technique (51\% of age models incorporate this method). Lead dating $\left({ }^{210} \mathrm{~Pb}\right)$ is used for 12 sediment chronologies. Many other lines of evidence are used in the North Pacific and marginal seas to develop paleoceanographic age models. These approaches vary regionally and include planktonic foraminifera oxygen isotope stratigraphy, diatom silica oxygen isotope stratigraphy, biostratigraphy, magnetostratigraphy, tephrochronology, chronostratigraphy, carbonate stratigraphy, opal stratigraphy, composition, lithological proxies, the presence of lamination, chlorin content, and color $\left(a^{*}, b^{*}\right.$, and $L^{*}$ values; Fig. 2, Table 3). For example, in the Sea of Japan, lithological proxies such as core laminations are often utilized as chronological proxy evidence, and $12 \%$ of local age models incorporate this technique. Tephrochronology is also applied in $51 \%$ of Sea of Japan age models due to regional volcanism. In the Bering Sea, peaks in silica are often used, and $13 \%$ of the regional age models incorporated this technique. Published sedimentation rates ranged across the North Pacific (0.1$\left.2000 \mathrm{~cm} \mathrm{ka}^{-1}\right)$, Bering Sea $\left(3-250 \mathrm{~cm} \mathrm{ka}^{-1}\right)$, Sea of Okhotsk $\left(0.7-250 \mathrm{~cm} \mathrm{ka}^{-1}\right)$, and the Sea of Japan $\left(0.2-74 \mathrm{~cm} \mathrm{ka}^{-1}\right)$ with the highest rates within the Alaska Current in the North Pacific (up to $2000 \mathrm{~cm} \mathrm{ka}^{-1}$ ).

\subsection{Paleoceanographic proxies from marine sediment cores}

From all reported sediment cores in the North Pacific and marginal seas, only $40 \%$ of cores have published proxy data (Figs. 3 and 5). Stable isotope stratigraphy was available for 293 cores, including oxygen, carbon, or nitrogen isotopes $\left(\delta^{18} \mathrm{O}, \delta^{13} \mathrm{C}, \delta^{15} \mathrm{~N}\right)$. We documented planktonic (236 cores) and benthic (178 cores) foraminiferal oxygen isotopes, planktonic (67 cores) and benthic (77) foraminifera carbon isotopes, and 34 cores with bulk sediment nitrogen isotopes. Of note, 98 cores were available with magnetostratigraphy (Table 4, Fig. 4).

We recorded paleothermometry data for 234 cores, including planktonic foraminifera oxygen isotopes, magnesium to calcium ratios from planktonic foraminifera, and alkenones $\mathrm{TEX}_{86}$ and $\mathrm{U}_{37}^{\mathrm{k}}$ (Fig. 3). We recorded 425 cores with microfossil biostratigraphy, including foraminifera, diatom, radiolarian, ostracod, silicoflagellate, ebridian, acritarch, coccolithophore, or dinoflagellate assemblages (Fig. 3, Table 4). Biostratigraphy utilizes known microfossil assemblages and their corresponding ages to assign a geologic age range to core strata containing assemblages. Geochemical analyses are reported for 151 cores, including measurements of, for example, brassicasterol, magnesium, calcium, molybdenum, 

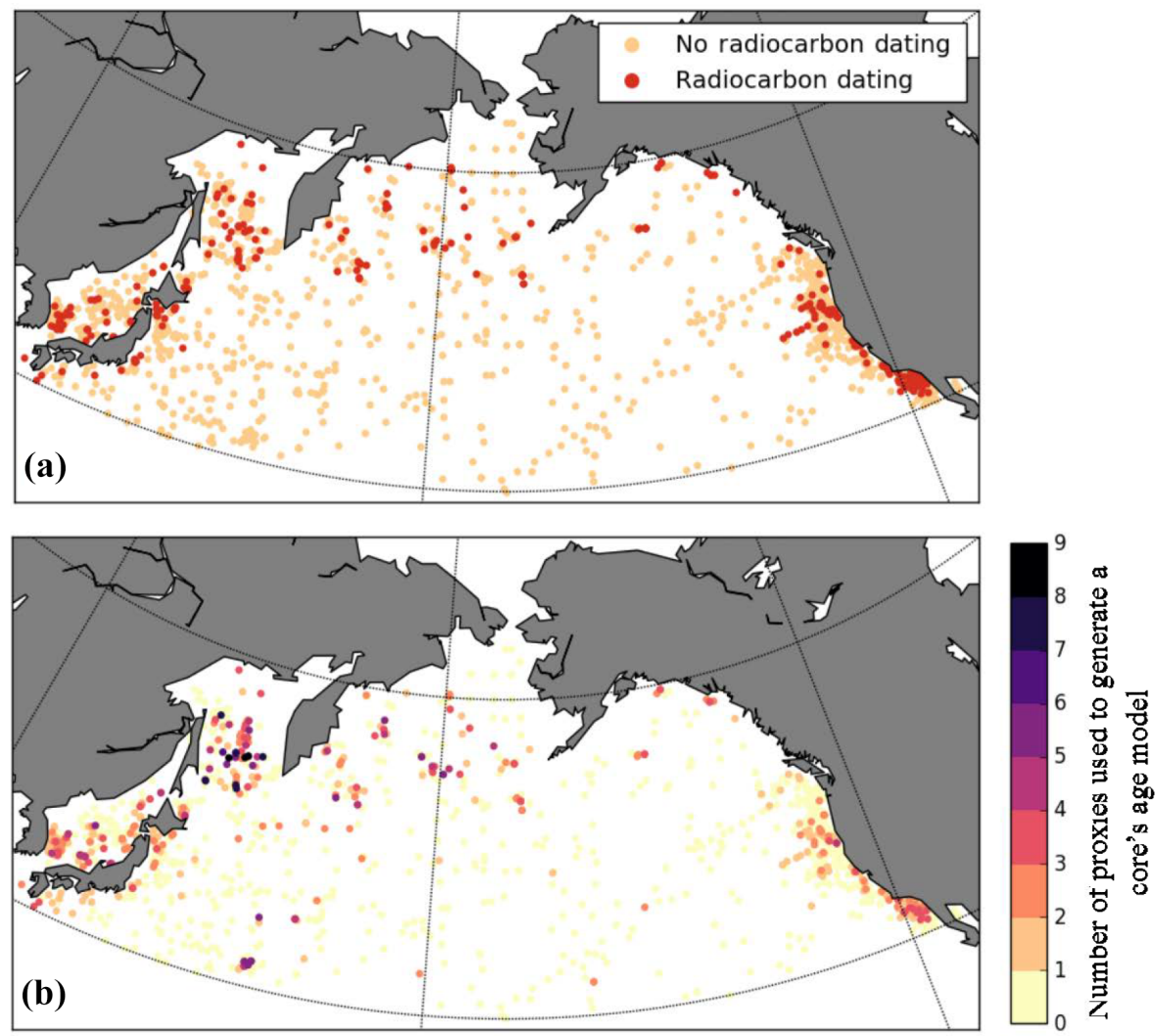

Figure 2. Age model development for sediment cores in the North Pacific and marginal seas. (a) Cores with age models that have been constructed with radiocarbon dating $\left({ }^{14} \mathrm{C}\right)$. (b) Number of paleoceanographic proxies used to generate each core's age model.

Table 3. Summary statistics on core chronology, including the number of cores with radiocarbon dating $\left({ }^{14} \mathrm{C}\right)$ and oxygen isotope stratigraphy of planktonic foraminifera $\left(\delta^{18} \mathrm{O}\right)$, as well as the regional mean core top and bottom ages, the number of cores with published sedimentation rate ranges and means, and core length minimums, maximums, and averages.

\begin{tabular}{lrrrr}
\hline Region & Bering Sea & North Pacific & Sea of Japan & Sea of Okhotsk \\
\hline${ }^{14}$ C dating & 28 & 158 & 38 & 42 \\
$\delta^{18}$ O stratigraphy, planktonic foraminifera & 20 & 122 & 29 & 32 \\
Mean core top age (calendar age, ka) & $6.0 \pm 9.6$ & $9.5 \pm 61.6$ & $5.9 \pm 28.4$ & $1.1 \pm 2.3$ \\
Mean core bottom age (calendar age, ka) & $523.7 \pm 1146.2$ & $6210.8 \pm 20250.7$ & $996.1 \pm 2602.2$ & $153.1 \pm 279.2$ \\
Cores with sedimentation rate range & 28 & 97 & 20 & 18 \\
Cores with sedimentation rate mean & 7 & 68 & 9 & 16 \\
Average core length (m) & 56.89 & 35.7 & 35.98 & 0.02 \\
Minimum core length (m) & 0.06 & 0.03 & 0.24 & 53.88 \\
Maximum core length (m) & 745 & 1180 & 555.3 & 6.50 \\
\hline
\end{tabular}

cadmium, manganese, uranium, chromium, rhenium, chlorin, titanium, iron, zinc, and beryllium (Fig. 3, Table 3). We documented 234 cores with sea ice proxy data, including geochemical biomarker IP25, ice-rafted debris (IRD), and diatom communities (Fig. 3). The presence and concentration of these proxies are indicative of contemporary sea ice extent and volume. We recorded 521 sediment cores with lithological analyses, including the documentation of core lamina, sediment density, mass accumulation rates, biogenic opal and barium, silicon to aluminum weight ratios, carbon to nitrogen ratios, inorganic and organic calcium carbonate and carbon, inorganic nitrogen, sulfur, and clay mineral composition (Fig. 3).

\subsection{Research cruise and publication rate}

We cataloged 565 peer-reviewed publications and cruise reports and evaluated the progress of paleoceanographic re- 

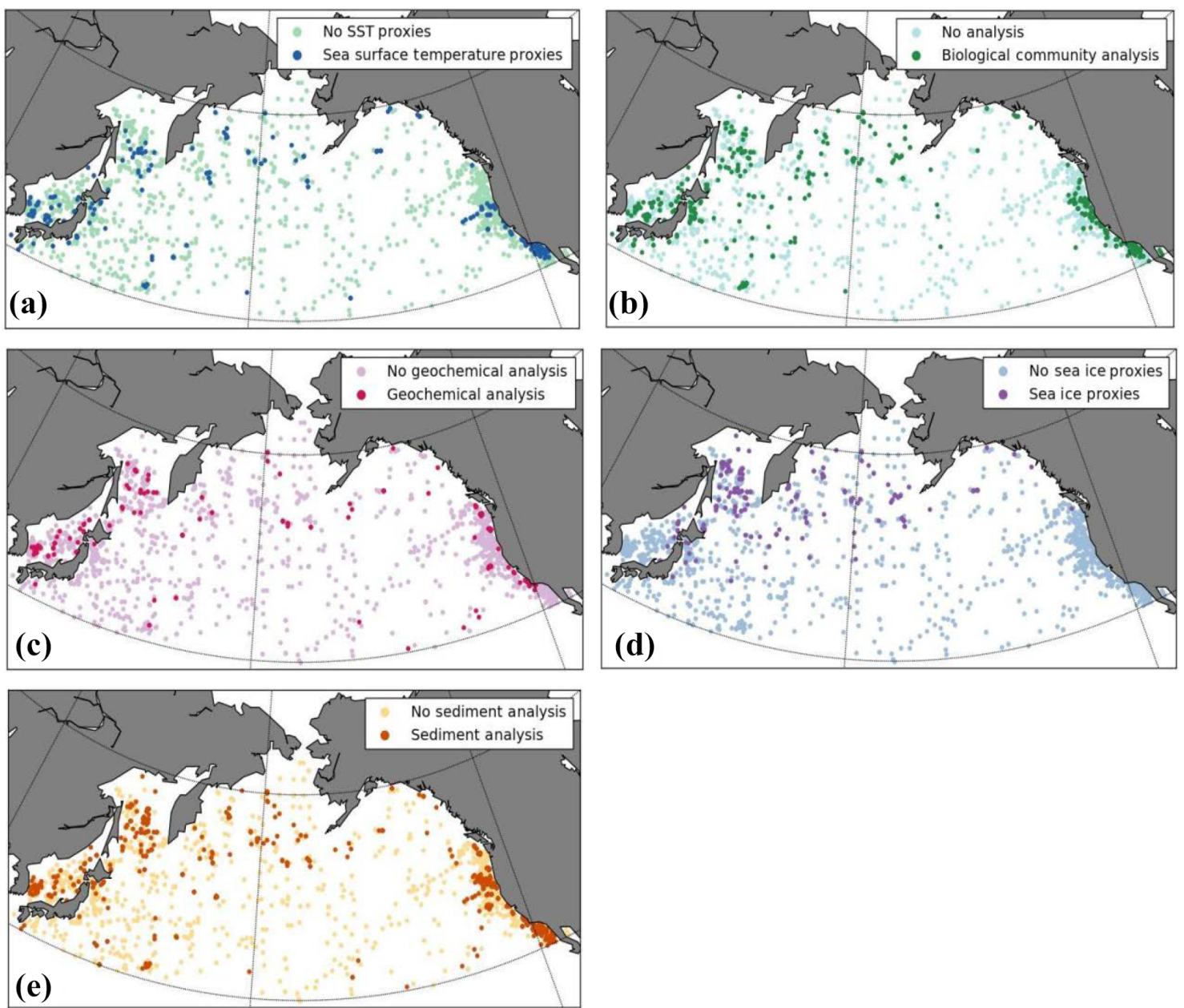

Figure 3. Published paleoceanographic proxies in the North Pacific. (a) Sea surface temperature reconstructions, including planktonic foraminifera oxygen isotopes $\left(\delta^{18} \mathrm{O}_{\mathrm{p}}\right)$, magnesium to calcium measurements, and $\mathrm{TEX}_{86}$ and $\mathrm{U}_{37}^{\mathrm{k}}$ alkenones. (b) Biostratigraphy of microfossils, including foraminifera, diatoms, radiolarians, ostracods, silicoflagellates, ebridians, acritarchs, coccolithophores, and dinoflagellates. (c) Geochemical proxy analysis, including trace metals such as brassicasterol, magnesium, calcium, molybdenum, cadmium, manganese, uranium, chromium, rhenium, chlorin, titanium, iron, zinc, and beryllium. (d) Presence of sea ice proxies, including geochemical biomarker IP25, ice-rafted debris (IRD), and sea-ice-related diatom communities. (e) Analysis of lithological core proxies, including 395 measurements of core lamina, biogenic opal and barium, silicon to aluminum weight ratio, sulfur, inorganic 20 and organic carbon weight and mass accumulation rates, mass accumulation rates of various elements, inorganic nitrogen, carbon to nitrogen ratios, sediment density, and clay mineral composition.

search using a suite of annual metrics of cruise and core metadata and publications (Fig. 5). The state of North Pacific paleoceanographic investigations has evolved incrementally in the 65-year history of research in the region, and we characterize the history into two distinct phases (before and after the early 1990s). Cruise reports were not publicly available for every cruise or core, and information on many cores cited in cruise reports was never published in peer-reviewed literature. The majority of cores (1210 cores or $57 \%$ of all cores extracted from the North Pacific) lack any publication.

Core recovery rates were high and publication rates were low from 1951 to 1988, which is a period when expeditions were driven by individual institutions and peer-reviewed publication was not the primary research outcome (Fig. 5). Annual rates of cruise completion and sediment core extraction peaked in 1965-1968, and this is a consequence of the temporal overlap in peak research efforts by the Scripps Institute of Oceanography (1951-1988), the Lamont-Doherty Earth Observatory (1964-1975), Oregon State University (1962-1972), and the Deep Sea Drilling Project (19711982). Annual rates of publication (peer-reviewed and cruise reports), including those publications with age models, increased around 1995 (Fig. 5). In this later period, research cruise efforts were dominated by international research team efforts and resulted in increased peer-reviewed publications, sediment core chronology constructions, and the prolifera- 

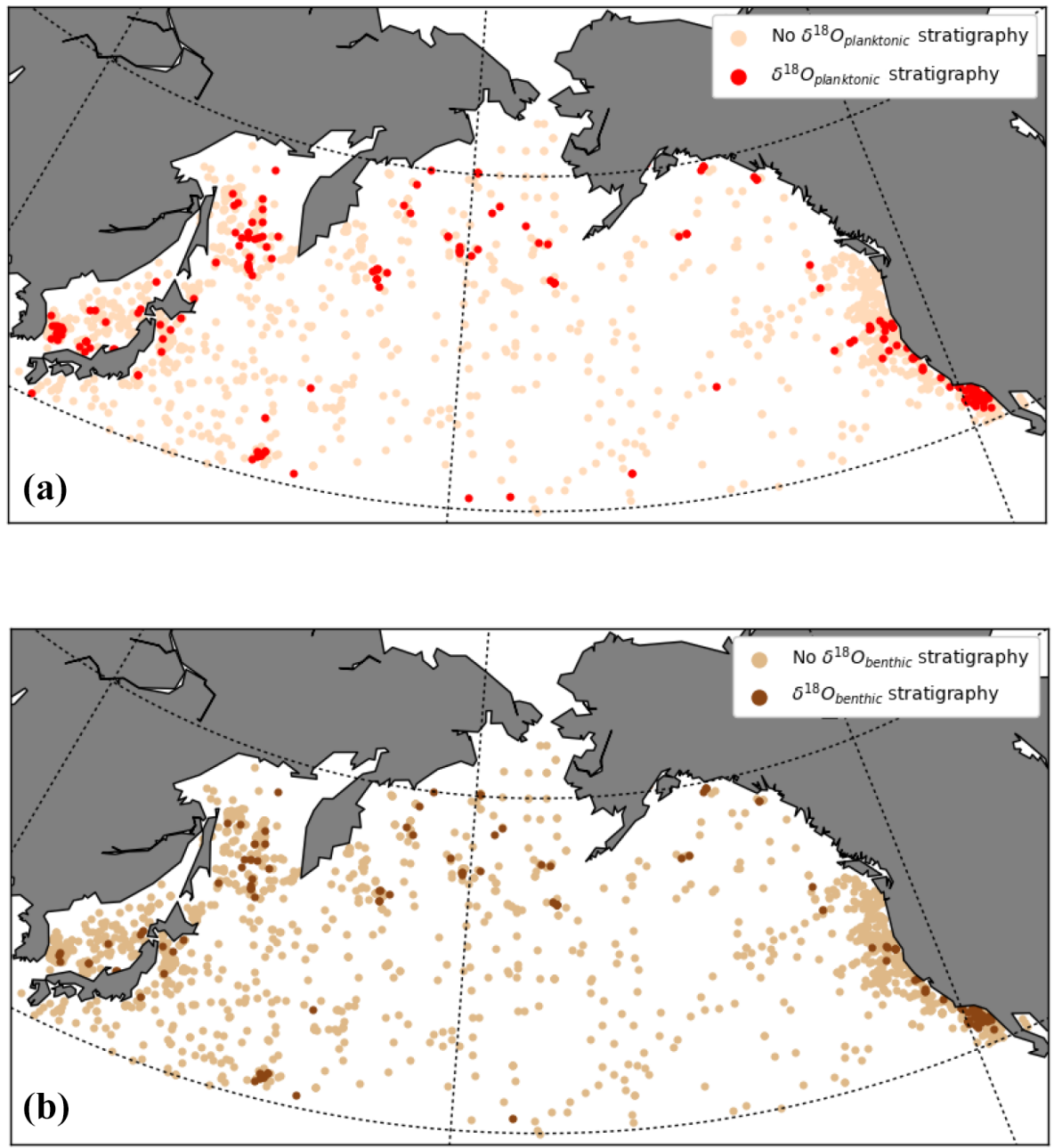

Figure 4. Published planktonic and benthic foraminiferal oxygen isotope stratigraphy for sediment core age models. (a) Analysis of planktonic foraminiferal oxygen isotopes and (b) analysis of benthic foraminiferal oxygen isotopes.

tion of radiocarbon dating. There are 41 cores with very focused investigation ( $>6$ publications), and these archives are primarily located within the California Current (Fig. 6). Major peaks in cruising and coring efforts coincided with research cruises by the International Ocean Discovery Program, such as ODP Legs 145 and 146 in 1992 (North Pacific transect, Cascadia margin), ODP Leg 167 in 1996 (California margin), and IODP Expedition 323 in 2009 (Bering Sea). Despite the increase in publications around 1995, we observe no distinct temporal trend in the rate of cruise completion and coring effort (Fig. 5).

\section{Code and data availability}

The database can be found online at https://doi.org/10.1594/PANGAEA.875998 from PANGAEA.

\section{Discussion}

\subsection{Evolving state of North Pacific coring and paleoceanographic approaches}

Extensive cruise and research efforts have focused on the marine geology of the North Pacific. Often, the cruise and core metadata from these efforts are unpublished, though they are integral to collaboration, continued research, and publication. Here we present a database with 2134 sediment cores, 283 research cruises, and 565 peer-reviewed publications related to paleoceanographic research (Table 1). We cataloged 519 publications with sedimentary age models, and of those age models, 266 utilized radiocarbon dating, 201 utilized planktonic foraminiferal oxygen isotope stratigraphy, and 129 utilized benthic foraminiferal oxygen isotope stratigraphy (Figs. 2 and 4). Throughout the North Pacific, Bering Sea, Sea of Okhotsk, and Sea of Japan, the techniques for reconstructing sedimentary age models var- 


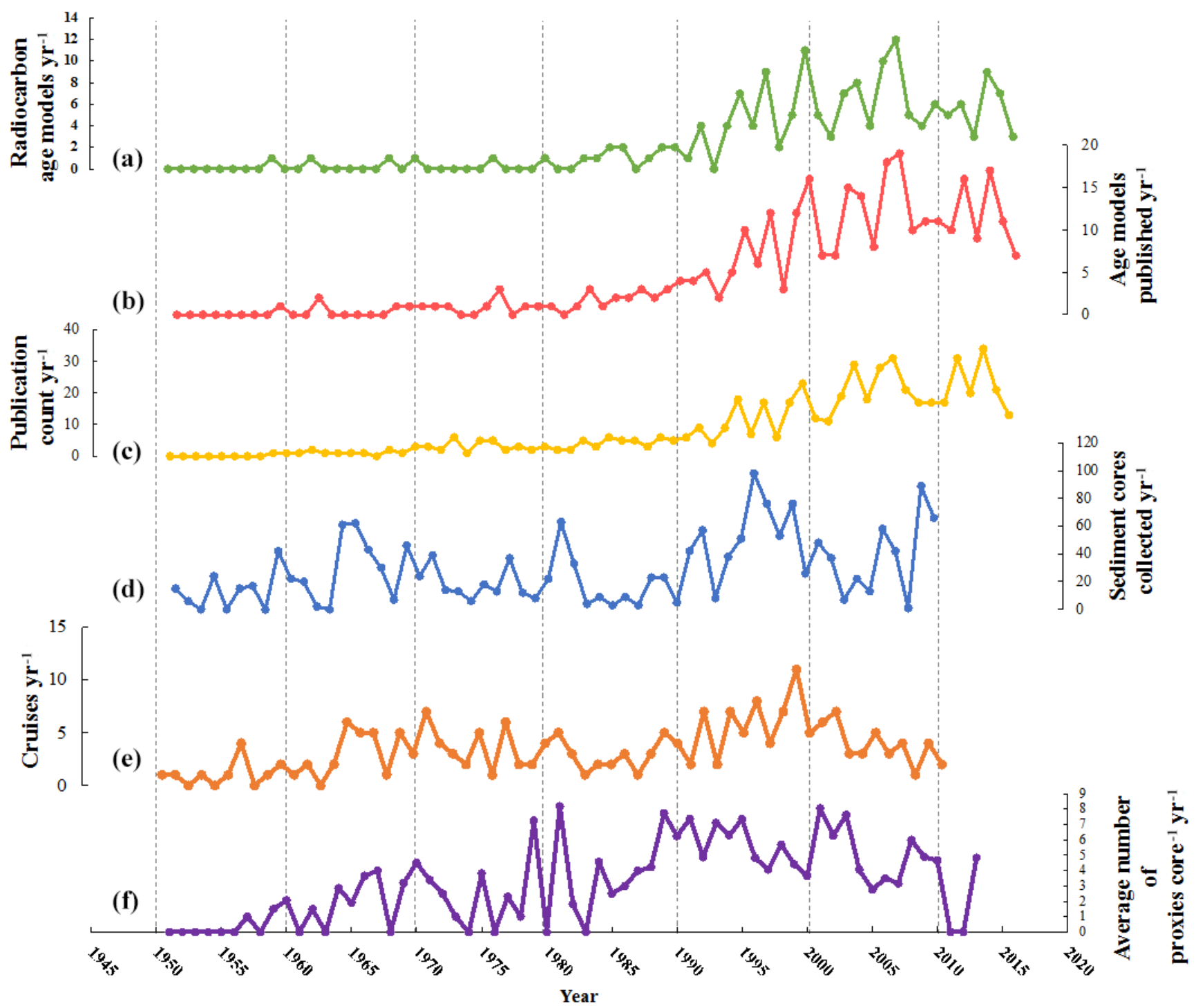

Figure 5. The marine geology cruise and paleoceanographic research progress through time for the North Pacific and marginal seas, wherein the lead-lag timing of cruise reporting and core publication is assumed for the most recent years. We utilize peer-reviewed publications to locate cores, and there is a lag between publication and core extraction. (a) Annual number of age models published using radiocarbon dating. (b) Annual number of all age models published. (c) Total annual number of publications and cruise reports. (d) Annual number of cores collected. (e) Marine research expedition count per year. (f) Annual mean number of proxy analyses published per core.

ied regionally. We documented a community-wide shift away from singular dating techniques toward age models that incorporate several techniques. Multiproxy approaches hold merit through verifying or constraining the results of a singular proxy and thereby disentangling multiple environmental drivers and providing redundancy in order to create robust records of climate and ocean conditions (Mix et al., 2000; Mann, 2002). Age model development has moved through the last 60 years to more detailed high-resolution age models constructed to investigate millennial and submillennial paleoceanographic variability (Figs. 5 and 6).

\subsection{The merit of database management and open-access science}

Databases are integral to facilitate efficient, hypothesis-based investigations into earth system mechanisms. Public access to databases facilitate a higher volume of research by a diverse range of scientists (Harnad and Brody, 2004). The necessity for databases to encompass a wide array of data over large oceanographic provinces is also largely recognized. Open access tools from PANGAEA support databasedependent research because hypothesis-based investigations can be more efficient through public data access. For ex- 
Table 4. Regional summary of isotopic, geochemical, biological, and sedimentary proxies. Benthic and planktonic isotopic analysis is for all cores, including, but not limited to, isotope analysis used in core chronology development.

\begin{tabular}{lrrrr}
\hline Region & Bering Sea & North Pacific & Sea of Japan & Sea of Okhotsk \\
\hline$\delta^{18} \mathrm{O}_{\text {benthic }}$ & 19 & 118 & 15 & 25 \\
$\delta^{18} \mathrm{O}_{\text {planktonic }}$ & 20 & 139 & 45 & 32 \\
$\delta^{13} \mathrm{C}_{\text {benthic }}$ & 7 & 57 & 7 & 6 \\
$\delta^{13} \mathrm{C}_{\text {planktonic }}$ & 6 & 50 & 10 & 1 \\
$\delta^{15} \mathrm{~N}$ & 5 & 16 & 12 & 1 \\
Alkenone $\mathrm{U}_{37}^{\mathrm{k}}$ & 7 & 64 & 15 & 12 \\
TEX & 0 & 1 & 0 & 0 \\
Foraminiferal biostratigraphy & 12 & 82 & 22 & 8 \\
Foraminiferal abundance & 8 & 53 & 41 & 18 \\
Diatom biostratigraphy & 35 & 87 & 49 & 25 \\
Coccolithophore biostratigraphy & 2 & 9 & 4 & 0 \\
Ostracod biostratigraphy & 1 & 1 & 2 & 0 \\
Geochemical proxies (Mg, Mo, & 1 & 189 & 46 & 27 \\
Cd, Mn, U, Cr, Re, Ca, T, Fe, Mg, & & & & \\
Zn, Be, chlorin) & & & & \\
$\%$ opal & 21 & 38 & 20 & 20 \\
Total inorganic carbon (\%) & 16 & 204 & 49 & 26 \\
Total organic carbon (\%) & 16 & 142 & 62 & 26 \\
\hline
\end{tabular}
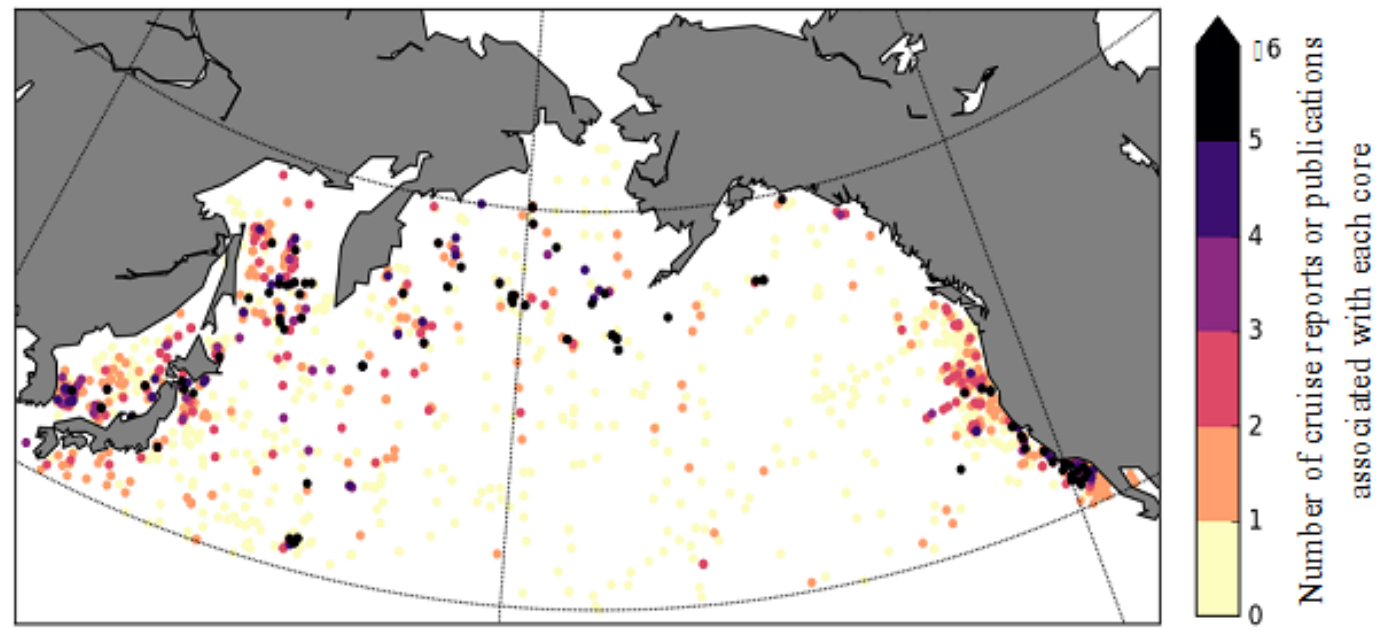

Figure 6. Number of affiliated publications and cruise reports for each core. The maximum publication count for an individual core is 23.

ample, content from online databases has contributed to research in atmospheric forcing (e.g., Shaffer et al., 2009), the Atlantic Meridional Overturning Circulation (AMOC; e.g., Schmittner and Galbraith, 2008), and Southern Ocean ventilation (e.g., Yamamoto et al., 2015). The metadata in these databases must be thorough, as data are impractical without the affiliated identifier, location, and methods (Lehnert et al., 2000). Database management should be a priority in any field that incorporates the contents of online repositories of knowledge and research. The disconnect between the research goals of the paleoceanographic community and the metadata produced here can be described as a "breakdown" that limits the progress of paleoceanographic research (Tanweer et al., 2016). These breakdowns allow us to self-assess and move forward with insight into best practices. Metadata are produced from data sets that are inherently human in design and are therefore not inerrant. Assessment of the errors in metadata reporting can directly reveal the need for community-wide improvements. As an example, all cores should be reported with latitude and longitude; the absence of these specific metadata significantly impairs further work. The database presented here and others like it consolidate the research effort of an entire community into an efficient tool for future investigative purposes. 


\subsection{Recommendations for the marine geology community}

Ocean sediment records are one of the primary tools for understanding earth's history, and the documentation of these records benefits the entire community of earth scientists. The publications and cruise reports here represent a large body of research completed on North Pacific sediment records; however, this may not constitute the entire body of work. There was no preexisting common repository for cruise reports and coring data in the North Pacific beyond the individual institutional archival processes. This database serves as the most complete archive of publicly available cruise reports and publications in which available DOIs and URLs are reported. We demonstrate a need for more thorough, accessible documentation of marine geology and paleoceanographic research. In our examination of publications, cruise reports, and notes from research cruises, we gained insights into past inconsistencies in marine sediment record reporting. We recommend a suite of actions to ensure efficient, comprehensive sediment core collection, metadata documentation, and the publication of chronologies and proxies. We propose that each publication thoroughly reports metadata on all cores discussed and their associated cruises, including core unique identifier numbers, cruise name and number, vessel name, geographic coordinates, core recovery date, core length, core recovery water depth ( $\mathrm{m}$ b.s.l.), sampling resolution, sampling volume, core archival repository, and the link (if existing) to public cruise reports. We also suggest summarizing each core's metadata, age model, and publication history in the methods section in order to provide a frame of reference for new findings, especially in the context of iterative age model revisions.

Author contributions. SEM and CVD initiated the building of this database. MB and SEM built the database and were joined by KASM in producing figures and analysis for this paper. All authors wrote the paper.

Competing interests. The authors declare that they have no conflict of interest.

Acknowledgements. The authors would like to thank the University of Washington Library oceanography collection, namely Louise Richards and Maureen Nolan. We also wish to acknowledge the support for this publication provided by the University of Washington Purple and Gold Scholarship, the UW School of Oceanography Lowell K. and Alice M. Barger Endowed Scholarship, the Clarence H. Campbell Endowed Lauren Donaldson Scholarship, the UW College of the Environment Student Travel Grant, and NSF grant OCE-1458967. KAS Mislan was supported by the Washington Research Foundation Fund for Innovation in Data-Intensive Discovery and the Moore/Sloan Data Science
Environments Project at the University of Washington.

Edited by: Attila Demény

Reviewed by: Baolin Liu and Thomas M. Cronin

\section{References}

Borreggine, M., Myhre, S. E., Mislan, K. A. S., Deutsch, C., and Davis, C. V.: A database of paleoceanographic sediment cores from the North Pacific, 1951-2016, PANGAEA, https://doi.org/10.1594/PANGAEA.875998, 2017.

CLIMAP Project Members: Seasonal reconstruction of the earth's surface at the last glacial maximum, Geological Society of America, Map and Chart Series 36, 18 pp., available at: https://www. ncdc.noaa.gov/paleo/metadata/noaa-ocean-2516.html, 1981.

Cook, M. S., Ravelo, A. C., Mix, A., Nesbitt, I. M., and Miller, N. V.: Tracing subarctic Pacific water masses with benthic foraminiferal stable isotopes during the LGM and late Pleistocene, Deep-Sea Res. Pt. II, 125, 84-95, https://doi.org/10.1016/j.dsr2.2016.02.006, 2016.

Davies, M. H., Mix, A. C., Stoner, J. S., Addison, J. A., Jaeger, J., Finney, B., and Wiest, J.: The deglacial transition on the southeastern Alaska Margin: meltwater input, sea level rise, marine productivity, and sedimentary anoxia, Paleoceanography, 26, PA2223, https://doi.org/10.1029/2010pa002051, 2011.

Di Lorenzo, E., Schneider, N., Cobb, K. M., Franks, P. J. S., Chha, K., Miller, A. J., McWilliams, J. C., Bograd, S. J., Arango, H., Curchitser, E., Powell, T. M., and Rivière., P.: North Pacific Gyre Oscillation links ocean climate and ecosystem change, Geophys. Res. Lett., 35, L08607, https://doi.org/10.1029/2007GL032838, 2008.

Harnad, S. and Brody, T.: Comparing the impact of open access (OA) vs. non-OA articles in the same journals, D-lib Magazine, 10, available at: https://eprints.soton.ac.uk/260207/, 2004.

Hendy, I. L., Pedersen, T. F., Kennett, J. P., and Tada, R.: Intermittent existence of a southern Californian upwelling cell during submillennial climate change of the last $60 \mathrm{kyr}$, Paleoceanography, 19, PA3007, https://doi.org/10.1029/2003pa000965, 2004.

Hoffert, M. I. and Covey, C.: Deriving global climate sensitivity from palaeoclimate reconstructions, Nature, 360, 573-576, https://doi.org/10.1038/360573a0, 1992.

Jaccard, S. L. and Galbraith, E. D.: Direct ventilation of the North Pacific did not reach the deep ocean during the last deglaciation, Geophys. Res. Lett., 40, 199-203, https://doi.org/10.1029/2012gl054118, 2013.

Knudson, K. P. and Ravelo, A. C.: North Pacific intermediate water circulation enhanced by the closure of the Bering Strait, Paleoceanography, 30, 1287-1304, https://doi.org/10.1002/2015PA002840, 2015a.

Knudson, K. P. and Ravelo, A. C.: Enhanced subarctic Pacific stratification and nutrient utilization during glacials over the last 1.2 Myr., Geophys. Res. Lett., 42, 9870-9879, https://doi.org/10.1002/2015GL066317, 2015b.

Lehnert, K., Su, Y., Langmuir, C. H., Sarbas, B., and Nohl, U.: A global geochemical database structure for rocks, Geochem. Geophy. Geosy., 1, 1012, https://doi.org/10.1029/1999gc000026, 2000. 
Mann, M. E.: Climate reconstruction: the value of multiple proxies, Science, 297, 1481-1482, https://doi.org/10.1126/science.1074318, 2002.

Max, L., Riethdorf, J.-R., Tiedemann, R., Smirnova, M., Lembke-Jene, L., Fahl, K., Nürnberg, D., Matul, A., and Mollenhauer, G.: Sea surface temperature variability and sea-ice extent in the subarctic northwest Pacific during the past 15000 years, Paleoceanography, 27, PA3213, https://doi.org/10.1029/2012PA002292, 2012.

Mix, A. C., Bard, E., Eglinton, G., Keigwin, L. D., Ravelo, A. C., and Rosenthal, Y.: Alkenones and multiproxy strategies in paleoceanographic studies, Geochem. Geophy. Geosy., 1, 1033, https://doi.org/10.1029/2000gc000056, 2000.

Pol-Holz, R. D., Ulloa, O., Dezileau, L., Kaiser, J., Lamy, F., and Hebbeln, D.: Melting of the Patagonian Ice Sheet and deglacial perturbations of the nitrogen cycle in the eastern South Pacific, Geophys. Res. Lett., 33, L04704, https://doi.org/10.1029/2005gl024477, 2006.

Praetorius, S. K., Mix, A. C., Walczak, M. H., Wolhowe, M. D., Addison, J. A., and Prahl, F. G.: North Pacific deglacial hypoxic events linked to abrupt ocean warming, Nature, 527, 362-366, https://doi.org/10.1038/nature15753, 2015.

Rae, J. W. B., Sarnthein, M., Foster, G. L., Ridgwell, A., Grootes, P. M., and Elliott, T.: Deep water formation in the North Pacific and deglacial $\mathrm{CO}_{2}$ rise, Paleoceanography, 29, 645-667, https://doi.org/10.1002/2013PA002570, 2014.

Schmittner, A. and Galbraith, E. D.: Glacial greenhouse-gas fluctuations controlled by ocean circulation changes, Nature, 456, 373-376, https://doi.org/10.1038/nature07531, 2008.
Serno, S., Winckler, G., Anderson, R. F., Hayes, C. T., Ren, H., Gersonde, R., and Haug, G. H.: Using the natural spatial pattern of marine productivity in the Subarctic North Pacific to evaluate paleoproductivity proxies, Paleoceanography, 29, 438-453, https://doi.org/10.1002/2013PA002594, 2014.

Shaffer, G., Olsen, S. M., and Pedersen, J. O. P.: Longterm ocean oxygen depletion in response to carbon dioxide emissions from fossil fuels, Nat. Geosci., 2, 105-109, https://doi.org/10.1038/ngeo420, 2009.

Tanweer, A., Fiore-Gartland, B., and Aragon, C.: Impediment to insight to innovation: understanding data assemblages through the breakdown-repair process, Information, Communication and Society, 19, 736-752, https://doi.org/10.1080/1369118x.2016.1153125, 2016.

Venti, N. L., Billups, K., and Herbert, T. D.: Paleoproductivity in the northwestern Pacific Ocean during the Pliocene-Pleistocene climate transition (3.0-1.8 Ma), Paleoceanography, 32, 92-103, https://doi.org/10.1002/2016PA002955, 2017.

Yamamoto, A., Abe-Ouchi, A., Shigemitsu, M., Oka, A., Takahashi, K., Ohgaito, R., and Yamanaka, Y.: Global deep ocean oxygenation by enhanced ventilation in the Southern Ocean under long-term global warming, Global Biogeochem. Cy., 29, 1801-1815, https://doi.org/10.1002/2015gb005181, 2015.

Zhang, C.: DeepDive: a data management system for automatic knowledge base construction, Thesis, available at: http://cs stanford.edu/people/czhang/zhang.thesis.pdf, 2015.

Zheng, Y., Geen, A. V., Anderson, R. F., Gardner, J. V., and Dean, W. E.: Intensification of the Northeast Pacific oxygen minimum zone during the BøllingAllerød Warm Period, Paleoceanography, 15, 528-536, https://doi.org/10.1029/1999pa000473, 2000. 